\title{
Combination therapy with PEG-IFN- $\alpha$ and 5-FU inhibits HepG2 tumour cell growth in nude mice by apoptosis of p53
}

\author{
S Hagiwara', M Kudo*,', T Nakatani', Y Sakaguchi', M Nagashima', N Fukuta', M Kimura ${ }^{2}$, S Hayakawa ${ }^{3}$ and \\ H Munakata ${ }^{3}$
}

'Department of Gastroenterology and Hepatology, Kinki University School of Medicine, Osaka-Sayama, Japan; ${ }^{2}$ Department of Pathology, Kinki University School of Medicine, Osaka-Sayama, Japan; ${ }^{3}$ Department of Biochemistry, Kinki University School of Medicine, Osaka-Sayama, Japan

\begin{abstract}
When the tumour suppressor p53 is activated by DNA damage, it stimulates the transcription of its target genes, which then induce cell cycle arrest or apoptosis. Here, we examined the role $\mathrm{p} 53$ plays in the antitumour effect of combination treatment with pegylated interferon (PEG-IFN)- $\alpha$ and 5-fluorouracil (5-FU), which has been shown to effectively treat advanced hepatocellular carcinoma (HCC). Nude mice were injected subcutaneously with cultured HepG2 cells, in which p53 is functional. They were treated a week later with PEG-IFN and/or 5-FU for 7 weeks, after which we measured and examined their tumours. Combination groups showed significantly lower tumour volumes and higher tumour cell apoptosis than the other groups. Combination treatment and PEG-IFN monotherapy also significantly elevated the $\mathrm{p} 53$ protein and mRNA levels in the tumour but only combination treatment increased the degree of p53 phosphorylation at serine 46 and induced p53-regulated apoptosis-inducing protein I (p53AIPI) expression. The antitumour effects of combination treatment is due in part to the elevation by PEG-IFN of p53 protein and mRNA expression and in part to the DNA damage that is generated by 5-FU, which induces p53 serine 46 phosphorylation, which in turn upregulates p53AIP I expression.
\end{abstract}

British Journal of Cancer (2007) 97, I532-1537. doi:I0.1038/sj.bjc.6604058 www.bjcancer.com

Published online 30 October 2007

(c) 2007 Cancer Research UK

Keywords: hepatocellular carcinoma; pegylated interferon; 5-fluorouracil; p53; apoptosis

Hepatocellular carcinoma (HCC) has a poor prognosis worldwide. Although the treatment of choice is generally resection, patients with HCC that is unresectable due to advanced disease or hepatic dysfunction are treated by radiofrequency ablation (RFA) and arterial embolisation. However, none of these local treatments are suitable for patients whose HCC has invaded the portal vein. Recent studies have suggested that these patients may be effectively treated by combination therapy involving subcutaneous (s.c.) administration of interferon (IFN)- $\alpha$ and intrahepatic administration of 5-fluorouracil (5-FU) (Sakon et al, 2002; Obi et al, 2006). A Phase II trial has also revealed that continuous 5-FU infusion combined with thrice-weekly treatment with IFN- $\alpha$ effectively treats HCC, perhaps because the drugs together play a neoadjuvant role (Patt et al, 2003). Comprehensive genetic analyses with PCR arrays have revealed that this method may be useful for predicting whether combination chemotherapy with IFN- $\alpha$ and 5-FU can successfully treat HCC (Kurokawa et al, 2004). However, despite these observations, the molecular mechanisms

*Correspondence: Professor M Kudo, Department of Gastroenterology and Hepatology, Kinki University School of Medicine, 377-2 OhnoHigashi, Osaka-Sayama 589-85II, Japan;

E-mail:m-kudo@med.kindai.ac.jp

Revised 24 August 2007; accepted I October 2007; published online 30 October 2007 behind the anti-HCC activity of IFN- $\alpha / 5$-FU combination therapy remain poorly understood.

The IFN- $\alpha$ group of closely related cytokines are typically produced early after infection with viruses and have antiviral and immunoregulatory activities (Samuel, 2001; Takaoka et al, 2003). They also have potent antitumour activities (Samuel, 2001; Takaoka et al, 2003). While studies examining the IFN- $\alpha$-mediated signal transduction pathways have already identified a number of IFN- $\alpha$-induced genes, it remains unclear whether these genes contribute to the antitumour activities of IFN- $\alpha$. The IFN- $\alpha$ cytokines appear to exert their antitumour activities both indirectly by activating immune cells such as natural killer cells, macrophages, and dendritic cells (Biron, 2001; Belardelli et al, 2002), and directly by inducing apoptosis (Clemens, 2003). With regard to the latter activity, the consensus IFN- $\alpha$, which is a nonnaturally occurring type I IFN with higher specific activity than the natural type I IFNs, has been shown to suppress the growth of HCC both in vitro and in vivo (Hisaka et al, 2004). Additional studies have suggested that pegylated interferon (PEG-IFN)- $\alpha$, where IFN- $\alpha$ is joined by an amide linkage to a $40 \mathrm{kDa}$ branched polyethylene glycol (PEG), may have even better antitumour effects in vivo. For example, Bailon et al (2001) showed that PEG-IFN- $\alpha$ has more potent antitumour activity on human kidney-derived cancer cells in vivo than IFN $\alpha$. The pegylation of IFN appears to stably maintain an effective concentration of IFN in the blood (Perry et al, 2001). 
The tumour suppressor gene $p 53$ is activated by the DNA damage that is induced by X-rays, ultraviolet (UV) rays, or anticancer drugs like 5-FU. Its protein then stimulates the transcription of its target genes, which induce cell cycle arrest or apoptosis. As a result, $p 53$ is frequently inactivated by mutations in tumour cells (Prives et al, 1999; Vogelstein et al, 2000; Vousden et al, 2002). Upon its phosphorylation at serine46, p53 also regulates the transcriptional activation of $\mathrm{p} 53$-regulated apoptosisinducing protein 1 (p53AIP1), which probably plays an important role in mediating p53-dependent apoptosis (Oda et al, 2000). Recently, the combination of $5-\mathrm{FU}$ and IFN- $\alpha$ was found to suppress HCC proliferation by elevating S-phase arrest and apoptosis (Kojiro et al, 2006). Given the central role p53 plays in the induction of cell cycle arrest and apoptosis, it is possible that the IFN- $\alpha / 5$-FU combination therapy activates p53 in some way. Supporting this is that IFN- $\alpha$ has been found to induce $p 53$ gene expression (Takaoka et al, 2003; Vilcek, 2003). To test whether p53 participates in the anti-HCC activity of IFN- $\alpha / 5-F U$ combination therapy, we here treated nude mice carrying HepG2 cell tumours with 5-FU and/or IFN- $\alpha$. HepG2 cells express functional p53. Our observations suggest that PEG-IFN- $\alpha$ elevates p53 protein expression, and that this, in combination with the DNA damage elicited by 5-FU, leads to enhanced HCC cell apoptosis in vivo.

\section{MATERIALS AND METHODS}

\section{Cell lines and cell culture}

The human HCC cell line HepG2 was obtained from the Health Science Research Resources Bank (Sennan, Japan) and was grown in Dullbecco's modified Eagle's medium (DMEM) (Sigma-Aldrich, St Louis, MO, USA) supplemented with $10 \%$ foetal bovine serum (FBS) (JRH Bioscience, St Lenexa, KS, USA) at $37^{\circ} \mathrm{C}$ under $5 \% \mathrm{CO}_{2} /$ 95\% air.

\section{Animals}

Male BALB/c nude mice, aged 4 weeks, were purchased from Clea Japan, Inc. (Tokyo, Japan) and acclimated for a week.

\section{Compounds and study design}

5-FU and PEG-IFN- $\alpha$ 2a (PEGASYS ${ }^{\circledR}$ ) were supplied by Kyowa Hakko Kogyo Co., Ltd (Tokyo, Japan) and Chugai Pharmaceutical Co., Ltd. (Tokyo, Japan), respectively. The 5-week-old male BALB/ c nude mice were injected s.c. with cultured HepG 2 cells $\left(10^{6}\right.$ cells per mouse). When the tumour was $5-10 \mathrm{~mm}$ in diameter (7 days later), the mice were randomly divided into five groups of five: Group 1 (control group) received phosphate-buffered saline (PBS), Group 2 (5-FU group) received $10 \mathrm{mg} \mathrm{kg}^{-1} \mathrm{day}^{-1} 5$-FU, Group 3 (high-dose 5-FU) received $20 \mathrm{mg} \mathrm{kg}^{-1}$ day $^{-1} 5$-FU, Group 4 (PEG-IFN) received $1.5 \mathrm{mg} \mathrm{kg}^{-1}$ PEG-IFN- $\alpha$, while Group 5 (combination) received $10 \mathrm{mg} \mathrm{kg}^{-1} 5$-FU and $1.5 \mathrm{mg} \mathrm{kg}^{-1}$ PEGIFN- $\alpha$. Note that Groups 2, 4, and 5 can be directly compared because they received the same doses of the two compounds. 5-FU was delivered intraperitoneally (i.p.) five times a week while PEGIFN- $\alpha$ was injected s.c. once a week. The animals were treated for 7 weeks. Tumour size was measured once a week in two directions by using calipers, and tumour volume was estimated by using the equation: length $\times(\text { the width })^{2}$ (each week)/the length $\times($ the width $)^{2}(0$ week $)$. At the end of the experiments, the mice were killed under ether anaesthesia and their tumours were examined as detailed below. All animal procedures were performed according to approved protocols and in accordance with the recommendations for the proper care and use of laboratory animals. The Medical Ethics Committee of Kinki University School of Medicine approved the study (October 2004).

\section{Histopathological examination and detection of apoptosis}

The tumours were resected and fixed in formalin. The tumour sections with the largest diameter were prepared as paraffin sections for haematoxylin and eosin (HE) staining. To detect apoptotic cells, the In situ Cell Death Detection Kit, TMR red (Roche Diagnostics GmbH, Mannheim, Germany) was used (TUNEL technology). The numbers of apoptotic cells in ten 1.35$\mathrm{mm}^{2}$ areas of each HE-stained specimen where apoptotic cells were present at a relatively uniform density were determined under a fluorescence microscope. These counts were averaged to obtain the number of apoptotic cells per specimen.

\section{Immunoprecipitation and immunoblot analysis}

Cell lysis, immunoprecipitation and immunoblotting were performed as described (Lehtonen et al, 2004). The p53 proteins were immunoprecipitated with an anti-p53 antibody (Ab-1; Oncogene Research Products, Cambridge, MA, USA) and immunoblotted by using rabbit IgG TrueBlot (eBioscience, San Diego, CA, USA) and anti-p53 or anti-p53-phospho-serine46 (Cell Signaling Technology, Danvers, MA, USA) antibodies. As a control, the supernatants obtained after p53 immunoprecipitation were directly subjected to immunoblotting with anti- $\beta$-actin antibody (Clone AC-74; SigmaAldrich, St Louis, MO, USA).

\section{RNA extraction and real-time RT - PCR}

Total RNA was isolated from the HepG2 tumours by employing an RNeasy Mini kit (Qiagen, Hilden, Germany). Total RNA $(200 \mu \mathrm{g})$ was converted into cDNA in accordance with the manufacturer's instructions (ReverTra Ace, TOYOBO, Osaka, Japan). The reaction was performed at $30^{\circ} \mathrm{C}$ for $10 \mathrm{~min}, 42^{\circ} \mathrm{C}$ for $20 \mathrm{~min}$, and $99^{\circ} \mathrm{C}$ for 5 min. Quantitative PCR was performed in 96-well plates by using the TaqMan probe assay (ABI Prism 7700; Perkin-Elmer, Waltham, MA, USA) (Eickhoff et al, 2000; Gautschi et al, 2001). For this, pairs of primers and TaqMan probes were designed by a PerkinElmer to amplify specific small fragments from p53 (Assay ID; Hs00153349) and p53AIP1 (Assay ID; Hs00223141). In addition, a pair of primers and a TaqMan probe designed for human glyceraldehyde-3-phosphate dehydrogenase (GAPDH) (PerkinElmer) were used as an internal standard of mRNA integrity within the experiment. The final reaction mixture contained $1 \times$ TaqMan Universal PCR Master Mix (AmpliTaq Gold, AmpErase UNG, dNTP and dUTG, and optimised buffer) (Perkin-Elmer), $1 \times$ p53 Mix or $1 \times$ p53AIP1 Mix, and $1 \times$ Control (GAPDH) Mix. The cycling conditions comprised an initial phase of $50^{\circ} \mathrm{C}$ for 2 and $10 \mathrm{~min}$ at $95^{\circ} \mathrm{C}$ that was followed by 50 cycles of $15 \mathrm{~s}$ at $95^{\circ} \mathrm{C}$ and $1 \mathrm{~min}$ at $60^{\circ} \mathrm{C}$.

\section{Statistical analyses}

The data are expressed as means \pm standard deviation. The statistical significance of differences between two groups was determined by Student's $t$-test. A probability value of 0.05 or less was considered to be significant.

\section{RESULTS}

\section{HepG2 tumour cell growth in nude mice}

The Group 3 mice, which received high-dose 5-FU $\left(20 \mathrm{mg} \mathrm{kg}^{-1}\right.$ day $\left.^{-1}\right)$, were excluded from the following analyses because they all died within 3 weeks of treatment.

High-dose 5-FU also induced marked weight loss (date not shown). In contrast, treatment with $10 \mathrm{mg} \mathrm{kg}^{-1}$ day $^{-1} 5$-FU and/or $1.5 \mathrm{mg} \mathrm{kg}^{-1}$ week $^{-1}$ PEG-IFN- $\alpha$ did not affect the body weight of the mice (data not shown). The volumes of the tumours over the 

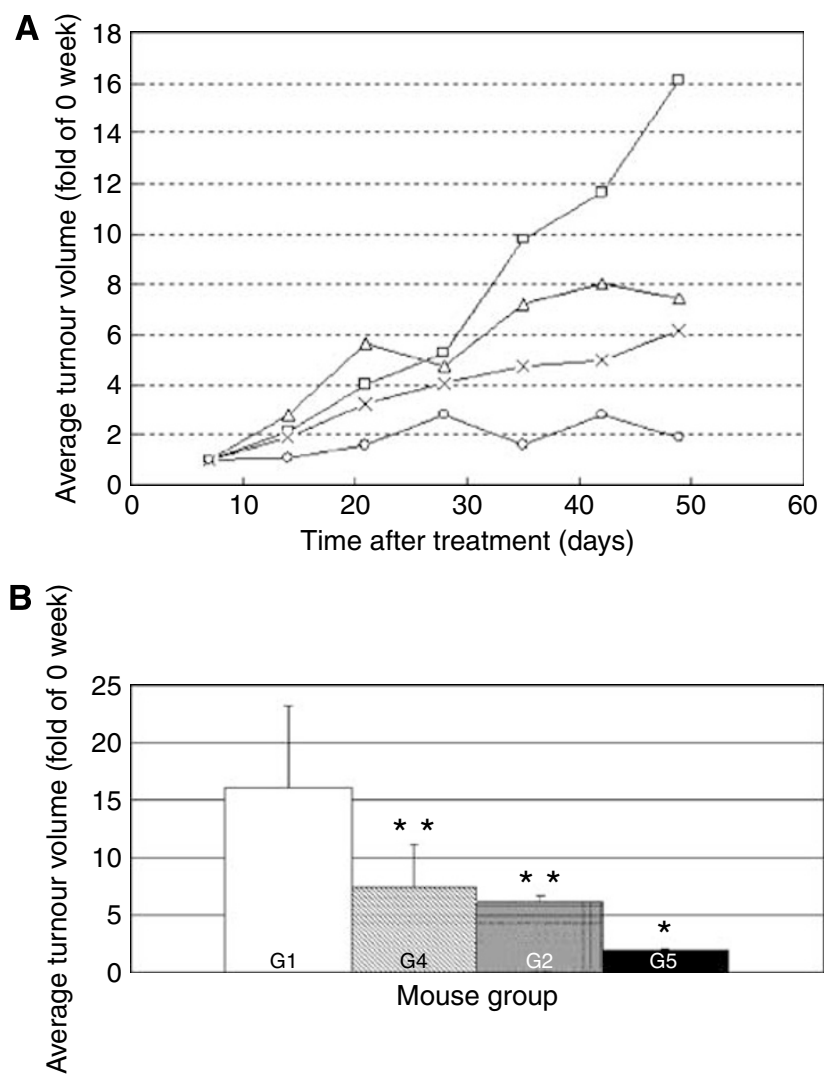

Figure I Tumour volumes of 5-FU- and/or PEG-IFN- $\alpha$-treated nude mice bearing s.c. HepG2 cell tumours. Mice bearing $5-10 \mathrm{~mm}$ diameter s.c. HepG2 cell tumours were treated with PBS (GI, control group), 5-FU at $10(\mathrm{G} 2,5-\mathrm{FU})$ or 20 (G3, high-dose 5-FU) $\mathrm{mg} \mathrm{kg}^{-1} \mathrm{day}^{-1}$ only, PEG-IFN- $\alpha$ at 1.5 (G4, PEG-IFN), or with both at $10 \mathrm{mg} \mathrm{kg}^{-1} \mathrm{day}^{-1} 5$-FU and $1.5 \mathrm{mg} \mathrm{kg}^{-1}$ week ${ }^{-1}$ PEG-IFN- $\alpha$ (G5, combination). (A) Change in tumour volume over time. $\mathrm{GI}(\square), \mathrm{G} 2(\times), \mathrm{G} 4(\Delta)$, and G5 $(\mathrm{O})$. The $\mathrm{G} 3$ group is not shown because these mice did not survive beyond 3 weeks of treatment. (B) Tumour volumes at the end of the experiment after 7 weeks of treatment. * Statistically significant difference compared with GI, $\mathrm{G} 2$, and $\mathrm{G} 4(P<0.05)$. *** Statistically significant difference compared with GI $(P<0.05)$.

7 weeks of treatment are shown in Figure 1A. When we compared the tumour volumes at the end of the experiment, Group 2 (5-FU), Group 4 (PEG-IFN), and Group 5 (combination) showed significantly lower tumour volumes than the control (Group 1). Furthermore, the tumour volumes of the combination group were significantly lower than those of the 5-FU and PEG-IFN monotherapy groups $(P<0.05$, Figure $1 \mathrm{~B})$.

\section{Histopathological examination and detection of apoptosis}

Photomicrographs of the HE-stained tumour sections taken from the control and combination-treated animals at the end of the experiment did not reveal any marked differences between the two groups, although the control group tumours did show some necrosis, unlike the combination group tumours. This is because the control group tumours were significantly larger. We then examined the 7-week tumour sections for apoptosis by TUNEL analysis. Representative TUNEL-stained tumour sections are shown in Figure 2A. The tumours from the combination-treated animals had significantly more apoptotic cells $\left(9.0 \pm 1.4 / 1.35 \mathrm{~mm}^{2}\right.$ area) than the tumours from all the other groups $(P<0.05$, Figure $2 \mathrm{~B})$. The tumours from the animals treated only with 5-FU $(6.2 \pm 0.7)$ or PEG-IFN $(4.6 \pm 0.8)$ also had significantly more apoptotic cells than the control tumours $(2.4 \pm 1.1)(P<0.05)$.
A
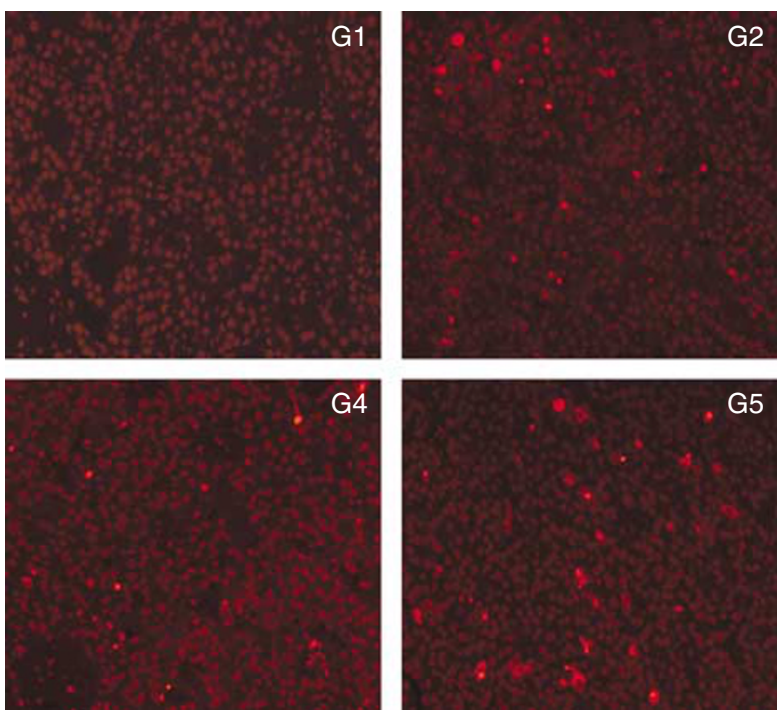

B

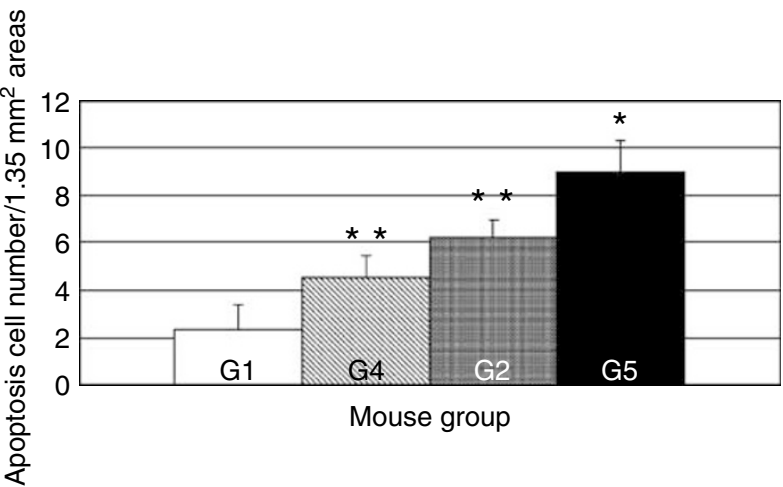

Figure 2 Incidence of apoptotic cells in TUNEL-stained 7-week tumour sections. The In situ Cell Death Detection Kit, TMR red was used to detect apoptotic cells in tumour sections. (A) Representative TUNEL-stained tumour sections from the GI (control), G2 (5-FU), G4 (PEG-INF), and G5 (combination) groups. $(\times \mid 00)$. (B) Average apoptotic cell numbers in TUNEL-stained tumour sections. Ten $1.35 \mathrm{~mm}^{2}$ areas in the HE-stained specimen that showed apoptotic cells in a relatively uniform density were selected for apoptotic cell counting. The 10 counts were then averaged to yield the data for the individual mice. The data shown are the average counts of the five mice in each group. The G5 tumours had significantly more apoptotic cells than all other groups, while the G2 and G4 tumours had significantly more apoptotic cells than the GI tumours. The error bar represents s.d. *Statistically significant difference compared with GI, G2, and G4 $(P<0.05)$. ***tatistically significant difference compared with $\mathrm{Gl}$ $(P<0.05)$.

\section{Immunoprecipitation, immunoblot analysis and real-time}

\section{RT - PCR}

We next determined the p53 protein and mRNA levels in the 7-week tumours by Western blot analysis and real-time RT-PCR, respectively (Figures 3 and 4). The degree of p53 phosphorylation on serine 46 protein and the p53AIP1 mRNA levels were also measured by Western blot analysis and real-time RT-PCR, respectively (Figures 3 and 4).

The extracted tumour proteins $(700 \mu \mathrm{g})$ were immunoprecipitated by using an anti-p53 antibody and then immunoblotted with anti-p53 or anti-p53-phospho-serine 46 antibodies. The combination- and PEG-IFN-treated tumours had higher p53 levels than the control and 5-FU-treated tumours. The degree of p53 phosphorylation on serine 46 was also significantly higher in the combination tumours than in the tumours of the other groups, which showed 
IP: anti-p53

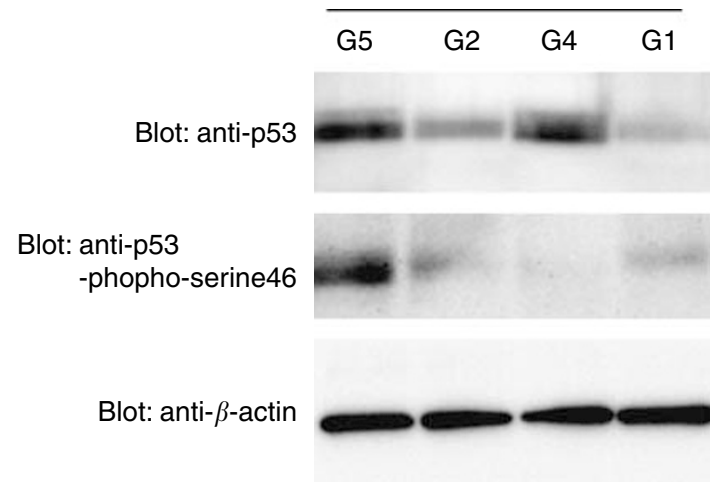

Figure 3 p53 levels and degree of p53 phosphorylation on serine46 in 7-week tumours. The extracted proteins $(700 \mu \mathrm{g})$ were subjected to immunoprecipitation with anti-p53 and immunoblot (Blot) analysis with anti-p53 or anti-p53-phospo-serine46 antibodies. As a control, the supernatants after p53 immunoprecipitation were directly subjected to immunoblotting using an anti- $\beta$-actin antibody. GI, control group; G2, 5-FU group; G4, PEG-IFN group; G5, combination group. The G4 and G5 tumours had higher p53 levels than the GI and G2 tumours while the combination tumours showed more $\mathrm{p} 53$ phosphorylation on serine 46 than the other tumours.
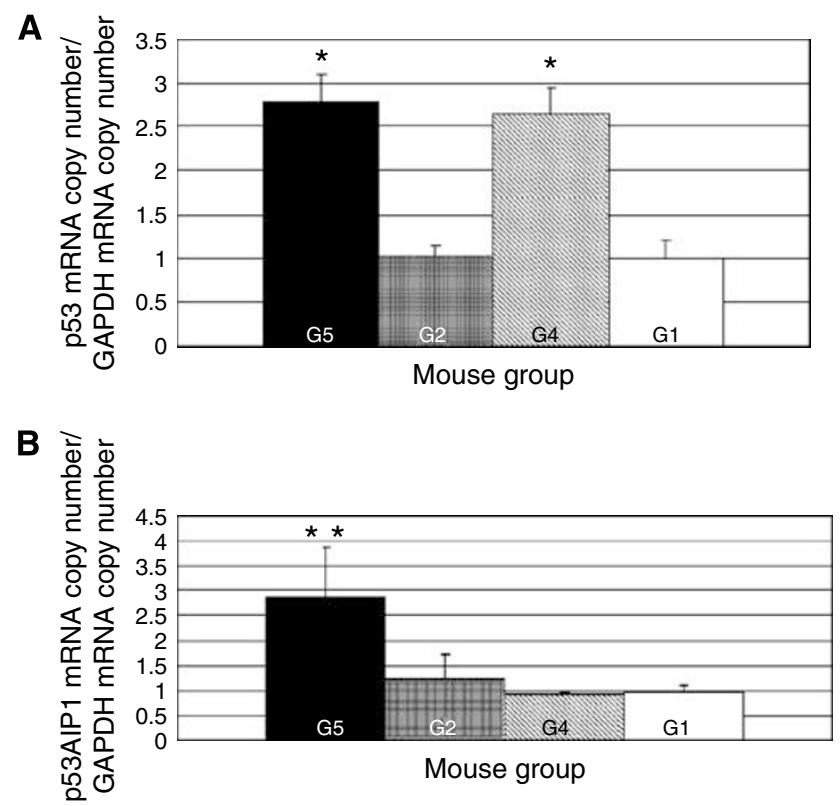

Figure 4 Quantitative RT-PCR analysis of p53 (A) and p53AIPI (B) mRNA expression in 7-week tumours. Total RNA $(200 \mu \mathrm{g})$ isolated from the HepG2 tumours was subjected to TaqMan real-time PCR. The data were analysed on the basis of the $C_{t}$ values of each sample and normalised relative to the GAPDH mRNA levels. The G4 and G5 groups showed increased p53 mRNA expression in their tumours compared to the $G I$ and G2 groups. The G5 tumours showed significantly increased p53AIP I mRNA levels when compared with the other tumours. The error bar represents s.d. *Statistically significant difference compared with GI and G2 $(P<0.05)$. **Statistically significant difference compared with GI, G2, and G4 $(P<0.05)$.

equivalent serine46 phosphorylation (Figure 3). When we examined the phosphorylation of p53 on serine 15 and serine 20 , none of the groups showed any differences (data not shown).

Figure 4A shows the expression of $p 53$ mRNA normalised to that of GAPDH. The expression of p53 mRNA in the combination- and
PEG-IFN-treated tumours was significantly increased about 2.7fold and about 2.6-fold in comparison to that in the control tumours, respectively. In addition, the level of p53AIP1 mRNA in the combination-treated tumours was significantly increased about 2.8 -fold when compared with that in the control tumours (Figure 4B).

\section{DISCUSSION}

Interferon- $\alpha$ treatment on its own has been known to have an antitumour effect (Biron, 2001; Belardelli et al, 2002; Clemens, 2003; Hisaka et al, 2004). Indeed, a previous study has shown that IFN- $\alpha$ directly prevents and delays hepatocarcinogenesis by suppressing pre-neoplastic cell proliferation although this study also found that this effect may depend in part on the induction of p21 via a p53-independent pathway (Nakaji et al, 2004). In addition, long-term, low-dose, intermittent IFN- $\alpha$ therapy was shown to successfully delay the clinical recurrence of HCC after radical RFA therapy (Sakaguchi et al, 2005). These observations are consistent with those of the present experiment, which revealed that treatment with PEG-IFN on its own quite efficiently suppressed tumour growth.

Their combination of IFN- $\alpha$ and 5 -FU has been shown previously to be highly effective clinically (Sakon et al, 2002; Patt et al, 2003; Obi et al, 2006). This is supported by our own observation that combination therapy with IFN- $\alpha$ and 5-FU induced significantly more apoptosis and tumour growth inhibition than monotherapy. This suggests that when IFN- $\alpha$ and 5-FU are combined, they act additively or synergistically to inhibit HCC. The mechanism behind this effect has been explored by several studies. One study reported that IFN- $\alpha$ activates thymidine phosphorylase (TP), which then metabolises 5-FU at higher rates, thereby increasing the intracellular levels of the active metabolite 5-fluoro-2'-deoxyuridine 5-monophosphate (FdUMP) (Schwartz et al, 1992). Interferon- $\alpha$ may also enhance the anti-HCC effect of capecitabine in nude mice by a similar mechanism (Xiao et al, 2004). Another study found that IFN- $\alpha$ inhibits thymidylate synthetases (TS), thereby enhancing 5-FU activity (Dou et al, 2005). In addition, the combination therapy has been shown to impair HCC growth by delaying the cell cycle and inducing apoptosis, since IFN- $\alpha / 5$-FU-treated human HCC cell lines show cell accumulation in the G0/G1 phase and increased expression of the cell cycle-related protein p27 ${ }^{\mathrm{Kip} 1}$ (Eguchi et al, 2000). Thus, it is possible that IFN- $\alpha$ and 5-FU may together induce cell cycle arrest and apoptosis. Various mechanisms may be involved in this effect. First, the known proapoptotic effect of 5-FU that arises from the DNA damage it causes may be augmented in an additive manner by IFN- $\alpha$, which may induce apoptosis by triggering the IFN- $\alpha / \beta$ receptor, which can then activate the signal transducer and activator of transcription (STAT)1 protein; STAT1 in turn regulates the expression of the Bcl-2 family of apoptosis-related proteins. Supporting the possibility that this mechanism is involved in the superior efficacy of the combination therapy, it has been noted that the growth-inhibitory effect of combination therapy is particularly marked in cell lines that express high levels of IFN- $\alpha / \beta$ receptors (Kondo et al, 2000, 2005; Ota et al, 2005). IFN- $\alpha$ and 5-FU may also act synergistically to induce HCC apoptosis due to the ability of both molecules to modulate the tumour necrosis factor-related apoptosis-induced ligand (TRAIL)/ TRAIL receptor-mediated cytotoxic pathway. Here, IFN- $\alpha$ elevates TRAIL expression by activating antitumour effectors while 5-FU enhances TRAIL-receptor expression by HCC cells (Yamamoto et al, 2004).

Our study here also suggests strongly that IFN- $\alpha / 5-\mathrm{FU}$ combination treatment induces apoptosis and suppresses HCC proliferation by activating mechanisms that involve p53. 853 plays an essential role in the induction of cell cycle arrest and apoptosis. 
That p53 may be involved in the superior efficacy of the combination treatment has been suggested previously by a study showing that the antitumour effects of 5-FU and cisplatin correlate with p53 activity (Longley et al, 2003; Mujoo et al, 2003). Moreover, the IFN-stimulated gene factor3 (ISGF3) formed by IFN $-\alpha$ has been shown to induce $p 53$ gene expression by binding to at least two IFN-stimulated response element (ISRE) sites in the p53 gene (Takaoka et al, 2003; Vilcek, 2003). We found that while the HepG2 tumours of PEG-IFN- and combination-treated animals showed significantly elevated p53 protein and mRNA levels, only the combination-treated tumours showed increased p53 phosphorylation at serine 46 and elevated p53AIP1 mRNA levels. P53AIP1 occurs only upon severe DNA damage, is activated by p53 after the latter is phosphorylated at serine 46 , and appears to control the apoptosis-inducing function of p53 (Oda et al, 2000). These observations together suggest that upon combination therapy, PEG-IFN increases p53 protein levels while 5-FU induces tumour cell DNA damage that activates the p53 molecules generated by PEG-IFN. This may be responsible, at least in part, for the superior apoptosis-inducing and tumour-inhibiting effects of this treatment regimen.

Notably, in the present experiment, none of the treatments altered the degree of $\mathrm{p} 53$ protein phosphorylation at serine 15 or serine20 (data not shown). After DNA damage, p53 phosphorylation first occurs at serine15 or 20 , which stabilises and activates p53; p53 then binds to the promoters of G1 arrest-related genes such as $\mathrm{p} 21^{\mathrm{waf} 1}$ and DNA repair-related genes such as p53R2 to induce their expression. If the DNA damage is severe enough, p53 then becomes phosphorylated at serine 46 and induces apoptosis. Since only the combination group showed significantly increased serine 46 phosphorylation, this suggests that the 5-FU component of this treatment regimen caused such severe DNA damage that the cells could not recover by inducing G1 arrest and DNA repair, thus resulting in serine 46 phosphorylation and HCC apoptosis.

In this study, to determine the role of p53 plays in PEG-IFN/ 5-FU combination treatment efficacy, we selected the HepG2 cell line, as its p53 molecule is functional and does not bear mutations. Clearly, cell in which p53 is mutated and dysfunctional or even lacking may be significantly less susceptible to PEG-IFN/5-FU combination therapy than HepG2. Indeed, when Takaoka et al (2003) compared the effect of combination therapy on the HLE cell line, in which p53 is dysfunctional, and HepG2 in vitro, they found that the therapy killed HepG2 but not HLE. Thus, future studies should examine whether p53-mutated or -negative tumour cells can be susceptible to combination therapy in vivo.

In conclusion, recent studies have reported that IFN/5-FU combination therapy can effectively treat patients with advanced HCC (Sakon et al, 2002; Obi et al, 2006). Our present study reveals PEG-IFN/5-FU combination therapy operates at least in part by enhancing the proapoptotic function of $\mathrm{p} 53$.

\section{REFERENCES}

Bailon P, Palleroni A, Schaffer CA, Spence CL, Fung WJ, Porter JE, Ehrlich GK, Pan W, Xu ZX, Modi MW, Farid A, Berthold W, Graves M (2001) Rational design of a potent, long-lasting form of interferon: a $40 \mathrm{kDa}$ branched polyethylene glycol-conjugated interferon alpha-2a for the treatment of hepatitis C. Bioconjug Chem 12: 195-202

Belardelli F, Ferrantini M, Proietti E, Kirkwood JM (2002) Interferon-alpha in tumor immunity and immunotherapy. Cytokine Growth Factor Rev 13: $119-134$

Biron CA (2001) Interferons alpha and beta as immune regulators - a new look. Immunity 14: $661-664$

Clemens MJ (2003) Interferons and apoptosis. J Interferon Cytokine Res 23: 277-292

Dou J, Iwashita Y, Sasaki A, Kai S, Hirano S, Ohta M, Kitano S (2005) Consensus interferon enhances the anti-proliferative effect of 5 -fluorouracil on human hepatoma cells via downregulation of dihydropyrimidine dehydrogenase expression. Liver Int 25: 148-152

Eguchi H, Nagano H, Yamamoto H, Miyamoto A, Kondo M, Dono K, Nakamori S, Umeshita K, Sakon M, Monden M (2000) Augmentation of antitumor activity of 5-fluorouracil by interferon alpha is associated with up-regulation of p27Kip1 in human hepatocellular carcinoma cells. Clin Cancer Res 6: $2881-2890$

Eickhoff B, Ruller S, Laue T, Kohler G, Stahl C, Schlaak M, van der Bosch J (2000) Trichostatin A modulates expression of p21waf1/cip1, Bcl-xL, ID1, ID2, ID3, CRAB2, GATA-2, hsp86 and TFIID/TAFII31 mRNA in human lung adenocarcinoma cells. Biol Chem 381: 107-112

Gautschi O, Tschopp S, Olie RA, Leech SH, Simoes-Wust AP, Ziegler A, Baumann B, Odermatt B, Hall J, Stahel RA, Zangemeister-Wittke U (2001) Activity of a novel bcl-2/bcl-xL-bispecific antisense oligonucleotide against tumors of diverse histologic origins. J Natl Cancer Inst 93: 463 471

Hisaka T, Yano H, Ogasawara S, Momosaki S, Nishida N, Takemoto Y, Kojiro S, Katafuchi Y, Kojiro M (2004) Interferon-alphaCon1 suppresses proliferation of liver cancer cell lines in vitro and in vivo. J Hepatol 41: $782-789$

Kojiro S, Yano H, Ogasawara S, Momosaki S, Takemoto Y, Nishida N, Kojiro M (2006) Antiproliferative effects of 5-fluorouracil and interferonalpha in combination on a hepatocellular carcinoma cell line in vitro and in vivo. J Gastroenterol Hepatol 21: 129-137

Kondo M, Nagano H, Sakon M, Yamamoto H, Morimoto O, Arai I, Miyamoto A, Eguchi H, Dono K, Nakamori S, Umeshita K, Wakasa K, Ohmoto Y, Monden M (2000) Expression of interferon alpha/beta receptor in human hepatocellular carcinoma. Int J Oncol 17(1): 83-88
Kondo M, Nagano H, Wada H, Damdinsuren B, Yamamoto H, Hiraoka N, Eguchi H, Miyamoto A, Yamamoto T, Ota H, Nakamura M, Marubashi S, Dono K, Umeshita K, Nakamori S, Sakon M, Monden M (2005) Combination of IFN-alpha and 5-fluorouracil induces apoptosis through IFN-alpha/beta receptor in human hepatocellular carcinoma cells. Clin Cancer Res 11: 1277-1286

Kurokawa Y, Matoba R, Nagano H, Sakon M, Takemasa I, Nakamori S, Dono K, Umeshita K, Ueno N, Ishii S, Kato K, Monden M (2004) Molecular prediction of response to 5-fluorouracil and interferon-alpha combination chemotherapy in advanced hepatocellular carcinoma. Clin Cancer Res 10: 6029-6038

Lehtonen S, Lehtonen E, Kudlicka K, Holthofer H, Farquhar MG (2004) Nephrin forms a complex with adherens junction proteins and CASK in podocytes and in Madin-Darby canine kidney cells expressing nephrin. Am J Pathol 165: 923-936

Longley DB, Harkin DP, Johnston PG (2003) 5-Fluorouracil: mechanisms of action and clinical strategies. Nat Rev Cancer 3: 330-338

Mujoo K, Watanabe M, Nakamura J, Khokhar AR, Siddik ZH (2003) Status of p53 phosphorylation and function in sensitive and resistant human cancer models exposed to platinum-based DNA damaging agents. J Cancer Res Clin Oncol 129: 709-718

Nakaji M, Yano Y, Ninomiya T, Seo Y, Hamano K, Yoon S, Kasuga M, Teramoto T, Hayashi Y, Yokozaki H (2004) IFN-alpha prevents the growth of pre-neoplastic lesions and inhibits the development of hepatocellular carcinoma in the rat. Carcinogenesis 25: 389-397

Obi S, Yoshida H, Toune R, Unuma T, Kanda M, Sato S, Tateishi R, Shiina S, Omata M (2006) Combination therapy of intraarterial 5-fluorouracil and systemic interferon-alpha for advanced hepatocellular carcinoma with portal venous invasion. Cancer 106: 1990-1997

Oda K, Arakawa H, Tanaka T, Matsuda K, Tanikawa C, Mori T, Nishimori H, Tamai K, Takino T, Nakamura Y, Taya Y (2000) p53AIP1, a potential mediator of p53-dependent apoptosis, and its regulation by Ser-46phosphorylated p53. Cell 102: 849-862

Ota H, Nagano H, Sakon M, Eguchi H, Kondo M, Yamamoto T, Nakamura M, Damdinsuren B, Wada H, Maruhashi S, Miyamoto A, Dono K, Umeshita K, Nakamori S, Wakasa K, Monden M (2005) Treatment of hepatocellular carcinoma with major portal vein thrombosis by combined therapy with subcutaneous interferon-alpha and intra-arterial 5 -fluorouracil; role of type 1 interferon receptor expression. $\mathrm{Br}$ J Cancer 93: $557-564$

Patt YZ, Hassan MM, Lozano RD, Brown TD, Vauthey JN, Curley SA, Ellis LM (2003) Phase II trial of systemic continuous fluorouracil and 
subcutaneous recombinant interferon alfa-2b for treatment of hepatocellular carcinoma. J Clin Oncol 21: $421-427$

Perry CM, Jarvis B (2001) Peginterferon-alpha-2a (40 kD): a review of its use in the management of chronic hepatitis C. Drugs 61: 2263-2288

Prives C, Hall PA (1999) The p53 pathway. J Pathol 187: $112-126$

Sakaguchi Y, Kudo M, Fukunaga T, Minami Y, Chung H, Kawasaki T (2005) Low-dose, long-term, intermittent interferon-alpha-2b therapy after radical treatment by radiofrequency ablation delays clinical recurrence in patients with hepatitis $\mathrm{C}$ virus-related hepatocellular carcinoma. Intervirology 48: $64-70$

Sakon M, Nagano H, Dono K, Nakamori S, Umeshita K, Yamada A, Kawata S, Imai Y, Iijima S, Monden M (2002) Combined intraarterial 5-fluorouracil and subcutaneous interferon-alpha therapy for advanced hepatocellular carcinoma with tumor thrombi in the major portal branches. Cancer 94: 435-442

Samuel CE (2001) Antiviral actions of interferons. Clin Microbiol Rev 14: $778-809$

Schwartz EL, Hoffman M, O'Connor CJ, Wadler S (1992) Stimulation of 5-fluorouracil metabolic activation by interferon-alpha in human colon carcinoma cells. Biochem Biophys Res Commun 182: 1232 - 1239
Takaoka A, Hayakawa S, Yanai H, Stoiber D, Negishi H, Kikuchi H, Sasaki S, Imai K, Shibue T, Honda K, Taniguchi T (2003) Integration of interferon-alpha/beta signalling to $\mathrm{p} 53$ responses in tumour suppression and antiviral defence. Nature 424: $516-523$

Vilcek J (2003) Boosting p53 with interferon and viruses. Nat Immunol 4: $825-826$

Vogelstein B, Lane D, Levine AJ (2000) Surfing the p53 network. Nature 408: $307-310$

Vousden KH, Lu X (2002) Live or let die: the cell's response to p53. Nat Rev Cancer 2: $594-604$

Xiao YS, Tang ZY, Fan J, Zhou J, Wu ZQ, Sun QM, Xue Q, Zhao Y, Liu YK, Ye SL (2004) Interferon-alpha 2a up-regulated thymidine phosphorylase and enhanced antitumor effect of capecitabine on hepatocellular carcinoma in nude mice. J Cancer Res Clin Oncol 130: 546-550

Yamamoto T, Nagano H, Sakon M, Wada H, Eguchi H, Kondo M, Damdinsuren B, Ota H, Nakamura M, Wada H, Marubashi S, Miyamoto A, Dono K, Umeshita K, Yagita H, Monden M (2004) Partial contribution of tumor necrosis factor-related apoptosis-inducing ligand (TRAIL)/TRAIL receptor pathway to antitumor effects of interferon-alpha/5-fluorouracil against hepatocellular carcinoma. Clin Cancer Res 10: 7884-7895 